University of Nebraska - Lincoln

DigitalCommons@University of Nebraska - Lincoln

2006

Interference Effects in the Memory for Serially Presented

Locations in Clark's Nutcrackers, Nucifraga columbiana

Jody L. Lewis

University of Nebraska-Lincoln

Alan C. Kamil

University of Nebraska-Lincoln, akamil1@unl.edu

Follow this and additional works at: https://digitalcommons.unl.edu/bioscibehavior

Part of the Behavior and Ethology Commons

Lewis, Jody L. and Kamil, Alan C., "Interference Effects in the Memory for Serially Presented Locations in Clark's Nutcrackers, Nucifraga columbiana" (2006). Papers in Behavior and Biological Sciences. 13.

https://digitalcommons.unl.edu/bioscibehavior/13

This Article is brought to you for free and open access by the Papers in the Biological Sciences at DigitalCommons@University of Nebraska - Lincoln. It has been accepted for inclusion in Papers in Behavior and Biological Sciences by an authorized administrator of DigitalCommons@University of Nebraska - Lincoln. 
Published in Journal of Experimental Psychology: Animal Behavior Processes 32:4 (2006), pp. 407-418; doi: 10.1037/0097-7403.32.4.407

Copyright ( 2006 by the American Psychological Association. Used by permission. "This article may not exactly replicate the final version published in the APA journal. It is not the copy of record." http://www.apa.org/journals/xan/

This experiment forms part of the dissertation of Jody L. Lewis. This research was supported by National Institutes of Health Grant MH-61810 and by a University of Nebraska - Lincoln Warden research grant. The authors thank Kazuhiro Goto for comments on drafts of this article.

Submitted June 15, 2005; revised June 21, 2006; accepted June 23, 2006.

\title{
Interference Effects in the Memory for Serially Presented Locations in Clark's Nutcrackers, Nucifraga columbiana
}

\author{
Jody L. Lewis \\ Department of Psychology, University of Nebraska - Lincoln \\ Alan C. Kamil \\ Department of Psychology and School of Biological Sciences, University of Nebraska - Lincoln \\ Corresponding author - Jody L. Lewis, Department of Psychology, \\ University of Wisconsin-Stevens Point, Stevens Point, WI 54481; email jody.lewis@uwsp.edu.
}

\begin{abstract}
The authors tested the spatial memory of serially presented locations in Clark's nutcrackers (Nucifraga columbiana). Birds were serially presented with locations in an open room. The authors buried a seed in a sand-filled cup at each location and then tested nutcrackers for their memory for each location in the list by using the cluster method. For each item in the list, the authors opened a cluster of 6 holes. Accuracy was measured by how many tries were required for the bird to find the correct location within each cluster. In Experiments 1 and 2, the authors presented 2 lists of locations and found evidence for proactive and retroactive interference. Nutcrackers made errors by visiting the interfering list of locations during recovery of the target list. This finding demonstrates that nutcrackers are susceptible to proactive and retroactive interference during the recall of spatial information.
\end{abstract}

Keywords: Nucifraga columbiana, Clark's nutcrackers, spatial memory, proactive interference, retroactive interference

Many seed-storing birds rely on memory to relocate stored food (Balda, 1980; Shettleworth \& Krebs, 1982; Vander Wall, 1982), but there are differences in memory abilities between species. Species differences in memory abilities often correlate with how much the species relies on food stores for survival and reproduction. For example, species that subsist primarily on stored food often perform more accurately during spatial memory tasks than species that are less dependent on stored food or do not store food at all (Balda, Kamil, \& Bednekoff, 1996; Shettleworth, 1995). One explanation for the differences found between food-storing and nonstoring birds is that storers are resistant to the effects of interference during spatial memory tasks (Clayton \& Krebs, 1994; Hampton \& Shettleworth, 1996; Hampton, Shettleworth, \& Westwood, 1998; Shettleworth \& Hampton, 1998).

Because interference effects could hamper recall of caches, they may be an important component of memory in food-storing birds. Extraneous information acquired close in time to acquisition of the target information could affect memory through interference effects. For example, spatial information obtained before placing caches could hamper recall of cache locations (proactive interference) as could spatial information obtained after the placement of caches but before their recovery (retroactive interference). Interference could also occur between memories for caches made the present year versus the previous year, between memories for caches located close to each other and encoded in terms of the same environmental cues, or between memories for full and depleted cache sites. Food-storing birds may be less susceptible to revisiting emptied sites than birds that do not store food (Clayton \& Krebs, 1994; Healy \& Krebs,
1992). Revisits to depleted cache sites pose a potential cost, in terms of both time and energy expended and exposure to predation. Food-storing birds therefore would be expected to be able to distinguish between full sites and sites that have been emptied (e.g., Clayton \& Krebs, 1994; Kamil, Balda, Olson, \& Good, 1993). Moreover, the ability to distinguish between full and empty cache sites may become increasingly important as cache recovery proceeds. As food is recovered, the number of emptied sites will eventually exceed the number of caches that still contain seeds (Vander Wall, 1990).

The potential importance of interference in food-storing birds is also suggested by the results of comparative tests of memory, which require birds to distinguish target information from previously acquired information. These experiments have found that species that are more dependent on recovery of stored food perform better than those species that are less dependent or do not store food at all. For example, among corvids, nutcrackers (Nucifraga columbiana) and pinyon jays (Gymnorhinus cyanocephalus) performed better than Western scrub jays (Aphelocoma californica) and Mexican jays (A. ultramarine) in a radial maze ana$\log$ (Kamil, Balda, \& Olson, 1994), which requires discriminating visited from nonvisited locations. Nutcrackers also remembered a location on a screen in an operant chamber better than pinyon jays, Western scrub jays, or Mexican jays during nonmatching-to-sample procedures (Olson, Kamil, Balda, \& Nims, 1995), which requires distinguishing a location that was rewarded during a previous trial from the correct location.

Similarly, among parids, storing species have performed better on tasks such as one-trial spatial associative learning. In the first phase of a one-trial memory test, birds are trained in 
an open room to search a set of feeders to find and eat part of a peanut in one feeder. In the second phase, the bird is allowed to search among the feeders and consume the rest of the peanut (e.g., Healy \& Krebs, 1992). During the second phase, nonstoring species were more likely than storing species to revisit any location they had visited during the first phase, even those that did not contain a seed. This suggests that food-storing birds are more resistant to interference from irrelevant stimuli, distinguishing memories for empty sites from sites that contain seeds (Clayton \& Krebs, 1994; Healy \& Krebs, 1992). Despite the results that suggest the importance of interference effects in food-storing birds, few studies have directly tested for such effects (see Bednekoff, Kamil, \& Balda, 1997; Hampton \& Shettleworth, 1996).

The study of the effects of interference on the spatial memory of Clark's nutcrackers would be particularly interesting. Nutcrackers are extremely dependent on cached pine seeds, subsisting almost exclusively on stored food to survive harsh winters. They store a large number of seeds (as many as 30,000$)$ and can remember cache locations for months at a time (Balda \& Kamil, 1992; Bednekoff et al., 1997; Tomback, 1980; Vander Wall \& Hutchins, 1983). Nutcrackers may be especially resistant to interference because of their neural structure. Compared with related species that do not rely as heavily on stored food, nutcrackers have a larger hippocampus (Basil, Kamil, Balda, \& Fite, 1996; Clayton, 1995; Healy \& Krebs, 1996; Sherry, Vaccarino, Buckenham, \& Herz, 1989; see also Krebs et al., 1996, for review), and it has been suggested that one function of the hippocampus is to reduce effects of interference (Shapiro \& Olton, 1994). Hampton and Shettleworth (1996) found that hippocampal lesions in food-storing chickadees resulted in higher susceptibility to intrusions from information from earlier test trials.

Nutcrackers appear to be resistant to proactive and retroactive interference during cache recovery (Bednekoff et al., 1997). Cache recovery techniques, however, may not be optimal for studying interference effects in spatial memory. A common procedure used with success in both humans and animals is the serial list method, in which the to-be-remembered stimuli or locations are presented serially and in controlled order. Such techniques have been used, for example, to study serial position effects (Wright, Santiago, Sands, Kendrick, \& Cook, 1985), to demonstrate the effects of trial-unique stimuli, and to study proactive interference within and between trials (Wright, Urcuioli, \& Sands, 1986).

The purpose of the experiments reported here was to develop a direct method for testing list learning in an open room and to then use the method to test interference effects in nutcrackers. The technique we developed to test serial memory was based on several earlier procedures. As in the "window shopping" method (e.g., Shettleworth, Krebs, Healy, \& Thomas, 1990), the bird is first rewarded in a particular location to which it must later return to obtain food. However, we adapted a procedure developed by Gibson (Gibson \& Kamil, 2001) in which pre-retention locations are presented singly. This provides a control for any order effects and, because the experimenter chooses the locations to be presented, also controls for site preferences and how often each rewarded location is used. To measure memory, we used the cluster technique developed by Kamil and Balda (1990; Kamil et al. 1993) in which a bird must find the correct location among a cluster of possible alternatives. The advantage of using the clus- ter method is that it allows us to measure the bird's memory for each location in the list. Opening all of the holes in the testing room would only allow us to compare the number of correct locations chosen with the total number of locations chosen. Therefore, by opening all of the locations, we would only have a gross measure of accuracy for the entire list. By testing performance for each location in the list, we can isolate factors that may influence nutcracker spatial memory such as position in a sequence and proactive and retroactive interference.

\section{Experiment 1: Proactive Interference}

The phenomenon in which information acquired earlier causes a decrement in the ability to recall later target information is known as proactive interference. In this experiment, birds were sometimes presented with one and sometimes with two lists in a day. We predicted that if nutcrackers are susceptible to proactive interference, they should perform worse during recall of the second list than during either the first list of that day or when they were given only a single list. We also predicted that when the incorrect alternate choices in a test of the second list included items that were correct in the previously presented list, birds would make more errors. This would demonstrate that nutcrackers are most susceptible to making errors when previously rewarded sites are nearby and/or reused as incorrect alternatives.

The purpose of the following experiments was to determine whether nutcrackers are susceptible to the effects of proactive and retroactive interference by using our method of testing serial memory. The effects of interference are strongest when old and new information is most similar (Wright et al., 1986). For food-storing birds, interference could occur between memories for different cache sites and could be most important in the case of caches that are in the same area or share the same environmental features. Furthermore, there could be significant interference between memories for sites that have previously been depleted and sites that still contain food. Kamil and Balda (1985) found that the two most common errors made by nutcrackers in cache-recovery experiments were revisits to depleted sites and visits to holes that were adjacent to the correct sites, which lends weight to these possibilities. Therefore, we designed these experiments to measure proactive (Experiment 1) and retroactive (Experiment 2) interference and to assess the effect of spatial proximity and revisits on the memory for lists of spatial locations.

\section{Method}

\section{Subjects}

Six wild-caught Clark's nutcrackers (Nucifraga columbiana), of unknown age and sex, were housed in individual cages in a room maintained at $22{ }^{\circ} \mathrm{C}$ with a 14:10-hr light-dark cycle. All 6 birds began training; however, 1 of the nutcrackers was removed from the testing procedure because of an injured foot. The birds were maintained on a diet of sunflower seeds, turkey starter, pellets, and a powdered vitamin supplement and kept at $85 \%-90 \%$ of their ad libitum weight. They were also fed mealworms, pine seeds, and had free access to water and grit. All of the birds had been used in other studies investigating how nutcrackers use distance and directional information from landmarks to locate a hidden goal (Goodyear \& Kamil, 2004) but were naive to methods used in this study. 


\section{Apparatus}

Each bird was carried from its home cage to a holding cage outside the testing room. The bird was kept in the holding cage until the experimental session began. From the holding cage, the birds could enter and exit the room through a porthole, which contained a sliding door located on the east wall. The testing room was $4.4 \times 2.7 \mathrm{~m}$ and contained a raised plywood floor, which was painted white. We drilled 176 holes (16 columns and 11 rows) in the floor. The holes were $9 \mathrm{~cm}$ in diameter and separated by $23 \mathrm{~cm}$ (center to center). Each hole contained a plastic cup that was filled with sand. Each hole could be closed with a plaster cap. The room contained 18 landmarks on the floor. Landmarks were made from a variety of materials including polyvinyl chloride piping, wood, and metal. All of the landmarks were cylindrical or rectangular in shape and were either positioned vertically or placed horizontally on the floor of the testing room. Each landmark was placed approximately $30-50 \mathrm{~cm}$ from the nearest landmark. We also made an effort to evenly distribute tall landmarks throughout the room. There were also two posters on the walls and two perches that remained in the same position throughout the entire experiment. Outside noise was masked by a speaker, placed on the floor in the southeast corner of the testing room, that projected white noise. A Panasonic WV-BL200 closed circuit camera was mounted in the center of the ceiling and sent a signal to a Sony Trinitron television and Sharp VC-A410 VCR outside the room. All trials were recorded on video tape, in case they needed to be reviewed, but the majority of scoring occurred during the trial. The two outermost columns of holes were not used for testing because they could not be included in the field of view of the camera.

\section{Procedure}

Acclimation. The purpose of this stage was to acclimate the nutcrackers to the testing room and to the general procedures. Each bird received one acclimation trial per day, for 5 days. Before each trial began, the bird was placed in a holding cage outside the testing room. A trial started with the bird's entry into the lighted testing room immediately after the lights were turned off in the holding area and the porthole was opened. When the bird first entered the room, all locations (holes) were closed except for two randomly chosen locations. These two locations each contained a portion of a pine seed on the surface of the sand. After the bird ate both seeds, the light was turned off in the room, the porthole was opened, and the light over the cage was turned on to encourage the bird to return to the holding cage. If the bird did not return within $5 \mathrm{~min}$, the experimenter entered the room and gently encouraged the bird to return. The bird then waited in the holding cage for 5 min while the experimenter opened the same two locations and placed a seed on top of the sand at each location. In order to familiarize the birds with the cluster method, we opened two clusters of locations. In each cluster, only the target location contained a seed on top of the sand. Three other adjacent locations were randomly selected to be opened in a 2 $\times 2$ pattern. After $5 \mathrm{~min}$, the birds were allowed back into the room to eat both seeds. Birds were then brought back into the holding cage after $5 \mathrm{~min}$ if they failed to eat both seeds.

Training. Throughout these experiments, we showed each bird a list of locations and then tested them for their memory of those locations. The length of the list was gradually increased over the course of training from two to four and then eight locations. List training consisted of three phases: study, retention, and recognition. In the study phase, each bird was given a serial presentation of the list locations. All of the holes in the room were closed with plaster caps except for the first location in the list. The experimenter buried a seed in the sand approximately $1 \mathrm{~cm}$ deep in the open cup. In order to minimize the possibility of satiation, we used only one quarter of a seed for each location. The bird was allowed to enter the room, locate the hole, and dig in the sand to recover the seed. Once the bird had eaten the seed, it was sent back into the holding cage outside the testing room. The bird remained in the holding cage while the experimenter cleaned up any spilled sand around the first location, closed it with a plaster cap, and buried a seed in the second location. This procedure was repeated for each location in the list. The interval between each presented location was approximately $30 \mathrm{~s}$ but varied depending on how long it took the bird to return to the holding cage.

After a bird had visited each location in the study phase, it spent a 10-min retention interval in the holding cage. During the interval, the experimenter set up the room for the recognition phase. During the recognition phase, the birds were allowed to enter the room and visit open holes until they found every seed present. We measured each bird's accuracy by using the cluster technique developed by Kamil, Balda, and their colleagues (Kamil \& Balda, 1990; Kamil et al., 1993). For list lengths of two and four locations, birds were tested with an equal number of "good" and "bad" clusters. For each location in the list, a good cluster was opened. A good cluster contained the correct location and three randomly selected adjacent holes in a square pattern. Each bad cluster contained a randomly selected group of four holes that did not contain any locations rewarded in the study phase.

The birds received one trial per day. During a trial, the bird was given a serial presentation of one list of locations and then given a memory test for those locations (see Table 1). Each trial consisted of a new list of locations. Each rewarded location in a list and its corresponding cluster were randomly chosen, with the restriction that one row and one column of closed holes surrounded each cluster. Each cluster could be directly adjacent to but not overlap clusters from the previous trial. Each rewarded location in a list was selected without replacement from all possible holes in the room (each hole was used as a rewarded location once approximately every 30 days).

During the recognition phase, the experimenter immediately recorded the sequence of visits the bird made into holes on a scoring sheet that resembled a map of the testing room. The coordinates of each location were indicated by a letter and number (e.g., B3, G12). Errors within a cluster were defined as the number of locations the bird visited in a good cluster before recovering the seed. Once the bird probed the sand within a cup, the location was considered visited. Revisits to the same location were not counted. With this method, we were able to test the bird's ability to distinguish the target location from its nearest neighbors. We also examined errors between good and bad clusters. We recorded visitation order and ranked the order of visits the bird made to each good and bad cluster.

The birds were trained with a list length of two locations for 70 days during which time the reward at each location was increased from a quarter to a half of a seed. The recognition phase during List Length 2 continued until the bird had either recovered all available seeds or visited all 16 holes. After the initial 10 trials, birds were allowed to visit up to 12 holes before the lights were turned off and the trial was ended. After Trial 31, birds were allowed to visit up to 8 holes before the trial ended. We then gave the birds a list length of four locations for the next 30 days. Each test continued until the bird had either recovered all seeds or visited 16 different holes.

During the final stage of training, the birds were given lists of 8 locations for 20 days. The spatial limitations in the room did not allow us to simultaneously test 16 clusters ( 8 good and 8 bad). Therefore, during the recognition phase of 8 locations lists, we opened only 8 good clusters. The recognition phase for a trial continued until the birds had either found all of the available seeds or visited 16 different holes.

Testing. Proactive interference testing was conducted for one trial per day for 5 days per week. A trial consisted of either the control condition (one list in a day) or the experimental condition (two lists in a day). All birds were tested in each condition. Each list consisted of five locations, so that the experimental condition would take only $30 \mathrm{~min}$ to complete.

The birds were randomly divided into two squads (a squad of 2 and a squad of 3). On the first day of testing, one randomly selected squad was given the control condition, and the other squad was given the experimental condition. On the next day, each squad was tested with the other condition, until each bird was tested 25 times in each condition over 50 days of testing. There was a retention interval of 5 min between the study phase and the recognition phase of each list. When the birds received two lists in a day, there was a 5-min interlist 
interval between the recognition phase of List 1 and the study phase of List 2 (see Table 1). During a trial, the control list received by one squad was identical to List 2 received by the other squad. This ensured that when comparisons were carried out accuracy across sessions, location in the room was controlled between the two types of lists. In order to prevent differences in satiation between the two conditions, when birds were tested with the control list for a given day, we gave them pine seeds in their home cage before running. The amount of seed was equal to the amount of food they would have received if they had received an additional list.

Cluster size in the recognition phase was six holes in a $2 \times 3$ array (see Figure 1). Birds were allowed to probe in the cluster until they either found the seed or probed four empty holes. The mean number of probes expected per cluster if a bird dug at random was 2.3, which was the mean probability of making zero, one, two, three, or four errors in a cluster of six holes. This was because we stopped the bird from probing in a cluster if they chose four holes without recovering a seed.

In order to control for the order of visitations to clusters, birds were only given one cluster at a time in which to probe for seeds. Therefore, only one cluster of six holes was opened at a time. After the bird had either found the seed or made four visits to different holes within a cluster, it then was prompted to leave the room when the lights were turned off in the testing room. It then waited in the holding cage as the experimenter set up the next cluster. The bird then reentered the room and was allowed to dig within the next cluster. This was repeated until all five list locations had been tested. The order in which nutcrackers were allowed to visit clusters was randomized by using a 5 (trial) $\times 5$ (study position) Latin square method. Every 5 days, we ran each item in the study sequence once in each possible recovery position. This was to control for possible effects of output interference, which occurs when the recall of information is hampered by material that has just been recalled (Tulving \& Arbuckle, 1966).

Birds received two types of clusters within the recognition phase of List 2: two repeat clusters and three unique clusters. Each repeat cluster contained one correct location, which was rewarded during the study phase of List 2. A repeat cluster also contained one interfering location, which had been rewarded during study and recognition of List 1 but was not rewarded during the recognition of List 2. Additionally, no List 1 cluster contained a rewarded location from List 2 . The remaining four locations within a repeat cluster were not rewarded during the trial. Unique clusters contained the correct location (the location that was rewarded during the study phase of List 2) and five locations that were not rewarded during the trial (see Figure 1).

\section{Results}

\section{Training List Length 2}

We carried out separate analyses of each list length during training. During the first stage, when list length was two, the birds accurately remembered the general area of the rewarded locations. A repeated measures analysis of variance (ANOVA) of Cluster Type $\times$ Block showed that birds visited good clusters significantly earlier than bad clusters, $F(1,5)$ $=7.68, p=.04$ (see Table 2). However, this pattern did not change significantly across blocks of 10 trials: there was no block main effect, $F(6,5)<1$, and no interaction, $F(6,5)=$ $1.35, p=.26$.

The birds showed excellent accuracy within clusters. If choosing randomly, a bird could make zero, one, two, or three errors before finding the seed, with a mean of 1.5 . The mean number of errors per cluster within the first seven blocks was $1.12( \pm 0.40 S E)$ significantly better than chance levels determined by a one-sample $t$ test, $t(5)=-6.10, p=$ .001. Furthermore, Figure 2 shows that overall performance improved throughout training, as nutcrackers made fewer errors per cluster as training proceeded, $F(6,5)=6.10, p=$ .001 .

\section{Training List Length 4}

An ANOVA showed that during the second stage, with List Length 4 , the nutcrackers continued to visit good clusters sooner than bad clusters, $F(1,5)=10.71, p=.02$ (see Table 2). Figure 2 shows that nutcrackers also showed improved performance on local accuracy over the three blocks, $F(2,5)=4.66$, $p=.04$. The mean number of errors within good clusters was $0.77( \pm 0.37)$, significantly better than chance, $t(5)=-8.28, p=$ .001 .

\section{Training List Length 8}

During the last stage, with List Length 8, only good clusters were presented to the birds during testing, so no comparison of good and bad clusters was possible. Figure 2 shows that the mean error per cluster was $0.72( \pm 0.82)$, which was significantly better than chance, $t(5)=-25.8, p=.001$. Because this stage was only run for two blocks, we did not conduct an analysis for change in performance.

\section{Testing}

We compared the birds' performance during three different list types: the list from the control condition, experimental List 1, and experimental List 2. Birds performed better than chance on all three list types, $t(4)=-49.24, p=.001$, but there

Table 1. Study Design of Training and of Experiments 1 and 2

\begin{tabular}{lc}
\hline \multicolumn{1}{c}{ Study } & Sequence of events \\
\hline Training (120 days) & \\
List Size 2 (70 days) & Study L1 $\rightarrow$ Recognition L1 \\
List Size 4 (30 days) & Study L1 $\rightarrow$ Recognition L1 \\
List Size 8 (20 days) & Study L1 $\rightarrow$ Recognition L1 \\
Experiment 1 (50 days) & Study L1 $\rightarrow$ Recognition L1 $\rightarrow$ Study L2 $\rightarrow$ Recognition L2 \\
Proactive interference & Study L2 $\rightarrow$ Recognition L2 \\
Control condition & Study L1 $\rightarrow$ Study L2 $\rightarrow$ Recognition L2 $\rightarrow$ Recognition L1 \\
Experiment 2 (50 days) & Study L1 $\rightarrow$ Recognition L1 \\
Retroactive interference &
\end{tabular}

$\mathrm{L}=$ list. 


\begin{tabular}{|c|c|c|c|c|c|c|}
\hline L1 Study & & 1 Recognition & & L2 Study & & L2 Recognition \\
\hline $\begin{array}{lllllllll}0 & 0 & 0 & 0 & 0 & 0 & 0 & 0 \\
0 & 0 & 0 & 0 & 0 & 0 & 0 & 0 \\
0 & 0 & 0 & 0 & 0 & 0 & 0 & 0 \\
0 & 0 & 0 & 0 & 0 & 0 & 0 & 0 \\
0 & 0 & 0 & 0 & 0 & 0 & 0 & 0 \\
0 & 0 & 0 & 0 & 0 & 0 & 0 & 0 \\
0 & 0 & 0 & 0 & 0 & 0 & 0 & 0 \\
0 & 0 & 0 & 0 & 0 & 0 & 0 & 0 \\
0 & 0 & 0 & 0 & 0 & 0 & 0 & 0 \\
0 & 0 & 0 & 0 & 0 & 0 & 0 & 0 \\
0 & 0 & 0 & 0 & 0 & 0 & 0 & 0\end{array}$ & $\begin{array}{c}5 \\
\min \\
\rightarrow\end{array}$ & $\begin{array}{llllllll}0 & 0 & 0 & 0 & 0 & 0 & 0 & 0 \\
0 & 0 & 0 & 0 & 0 & 0 & 0 & 0 \\
0 & 0 & 0 & 0 & 0 & 0 & 0 & 0 \\
0 & 0 & 0 & 0 & 0 & 0 & 0 & 0 \\
0 & 0 & 0 & 0 & 0 & 0 & 0 & 0 \\
0 & 0 & 0 & 0 & 0 & 0 & 0 & 0 \\
0 & 0 & 0 & 0 & 0 & 0 & 0 & 0 \\
0 & 0 & 0 & 0 & 0 & 0 & 0 & 0 \\
0 & 0 & 0 & 0 & 0 & 0 & 0 & 0 \\
0 & 0 & 0 & 0 & 0 & 0 & 0 \\
0 & 0 & 0 & 0 & 0 & 0 & 0 & 0\end{array}$ & $\begin{array}{c}5 \\
\min \\
\rightarrow\end{array}$ & $\begin{array}{lllllllll}0 & 0 & 0 & 0 & 0 & 0 & 0 & 0 \\
0 & 0 & 0 & 0 & 0 & 0 & 0 & 0 \\
0 & 0 & 0 & 0 & 0 & 0 & 0 & 0 \\
0 & 0 & 0 & 0 & 0 & 0 & 0 & 0 \\
0 & 0 & 0 & 0 & 0 & 0 & 0 & 0 \\
0 & 0 & 0 & 0 & 0 & 0 & 0 & 0 \\
0 & 0 & 0 & 0 & 0 & 0 & 0 & 0 \\
0 & 0 & 0 & 0 & 0 & 0 & 0 & 0 \\
0 & 0 & 0 & 0 & 0 & 0 & 0 & 0 \\
0 & 0 & 0 & 0 & 0 & 0 & 0 & 0 \\
0 & 0 & 0 & 0 & 0 & 0 & 0 & 0\end{array}$ & $\begin{array}{c}5 \\
\min \\
\rightarrow\end{array}$ & $\begin{array}{llllllll}0 & 0 & 0 & 0 & 0 & 0 & 0 & 0 \\
0 & 0 & 0 & 0 & 0 & 0 & 0 & 0 \\
0 & 0 & 0 & 0 & 0 & 0 & 0 & 0 \\
0 & 0 & 0 & 0 & 0 & 0 & 0 & 0 \\
0 & 0 & 0 & 0 & 0 & 0 & 0 & 0 \\
0 & 0 & 0 & 0 & 0 & 0 & 0 & 0 \\
0 & 0 & 0 & 0 & 0 & 0 & 0 & 0 \\
0 & 0 & 0 & 0 & 0 & 0 & 0 & 0 \\
0 & 0 & 0 & 0 & 0 & 0 & 0 & 0 \\
0 & 0 & 0 & 0 & 0 & 0 & 0 & 0 \\
0 & 0 & 0 & 0 & 0 & 0 & 0 & 0\end{array}$ \\
\hline
\end{tabular}

\begin{tabular}{|l|}
\hline Legend \\
Represents a closed hole. \\
Represents an open hole in a cluster. \\
Is a rewarded location from list 1. \\
Is a rewarded location from list 2. \\
Represents a hole that was previously open in a \\
list 1 cluster but is not open during recognition of list 2. \\
\hline
\end{tabular}

Figure 1. Diagram of the testing room for study and recognition of Lists 1 and 2 for Experiment $1 . \mathrm{L}=$ list

were differences in performance among the types, as shown by a repeated measures ANOVA, $F(2,4)=77.93, p=.001$. We used Fisher's least significant difference (LSD) tests, with an alpha level of .05 , for all subsequent tests for significant $F$ values. LSD tests revealed that there was no significant difference in number of errors during the control list and during List 1 testing $(M=0.75 \pm 0.05)$ but that performance during List $2(M$ $=1.09 \pm 0.05)$ testing was significantly worse than performance during either List 1 or control list testing.

We also carried out a more detailed analysis of performance during List 2 testing. We compared error among three cluster types, repeat (clusters during List 2 testing that contained a List 1 site), unique (clusters during List 2 testing that did not contain a List 1 site), and control (clusters during testing of the control list) clusters. We used the control condition again, in this analysis, in order to provide a no interference control that could be compared with each interference manipulation in List 2. Figure 3 shows the mean number of errors made during testing in control, unique, and repeat clusters. There were significant differences among these cluster types, $F(2,4)=39.90$, $p=.001$. A Fisher's LSD test revealed that the mean number of

Table 2. Rank Order of Visits Into Good and Bad Clusters for List Sizes 2 and 4

\begin{tabular}{cccccc}
\hline & \multicolumn{2}{c}{ Good clusters } & & \multicolumn{2}{c}{ Bad clusters } \\
\cline { 2 - 3 } \cline { 5 - 6 } List size & $M$ & $S E$ & & $M$ & $S E$ \\
\hline 2 & 2.32 & 0.37 & & 2.67 & 0.38 \\
4 & 3.68 & 0.16 & & 5.30 & 0.15 \\
\hline
\end{tabular}

errors for each cluster type was significantly different than for all other cluster types. The birds made significantly more errors in repeat clusters than in either unique or control clusters, and significantly more errors in unique clusters than in control clusters.

We also examined the mean probability that a bird would make its first visit to each location within a repeat cluster. Figure 4 shows the mean number of visits made to correct, interference, and other locations within a cluster. There was a main effect of location, $F(2,4)=20.58, p=.001$. We found, using Fisher's LSD test, that birds were more likely to make their first choice to the correct or interfering location from List 1 than any other incorrect location. Nutcrackers were much less likely to visit other incorrect holes in the cluster.

Nutcrackers' overall performance was above chance because they made few visits to locations that were never rewarded during List 1 or List 2 . The first visit within a cluster was equally likely to be to a location rewarded in List 1 as to a correct location in List 2.

\section{Discussion}

This experiment demonstrates that studying memory for spatial lists of locations is a successful way of testing spatial memory in Clark's nutcrackers. This technique allowed us to control the choice of testing locations and allowed us to measure memory for each individual location in the list. The birds learned the task quickly and performed well. 


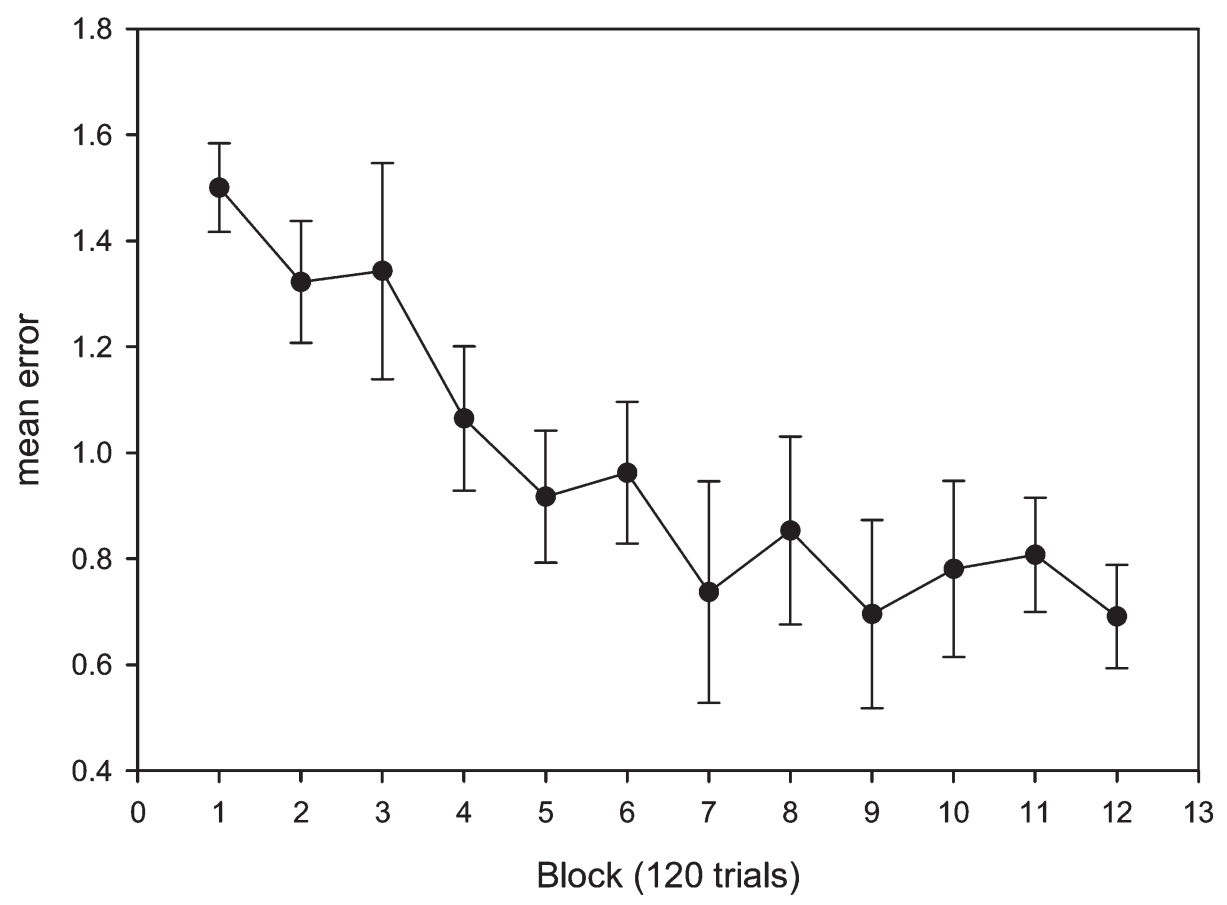

Figure 2. Mean error per cluster by block during Experiment 1. In the first seven blocks, birds were given List Length 2. In Blocks 8-10, birds were given List Length 4. In Blocks 11 and 12, birds were given List Length 8. Error bars represent standard error

The results clearly demonstrate that Clark's nutcrackers are susceptible to proactive interference during the recall of spatial locations. This is the first clear demonstration of interference when testing nutcrackers in an open room. Performance was less accurate during List 2 testing than during either List 1 or control testing. The interference appeared to be due to two factors, the use of the same locations in both lists and general proximity between locations. We discuss these separately.

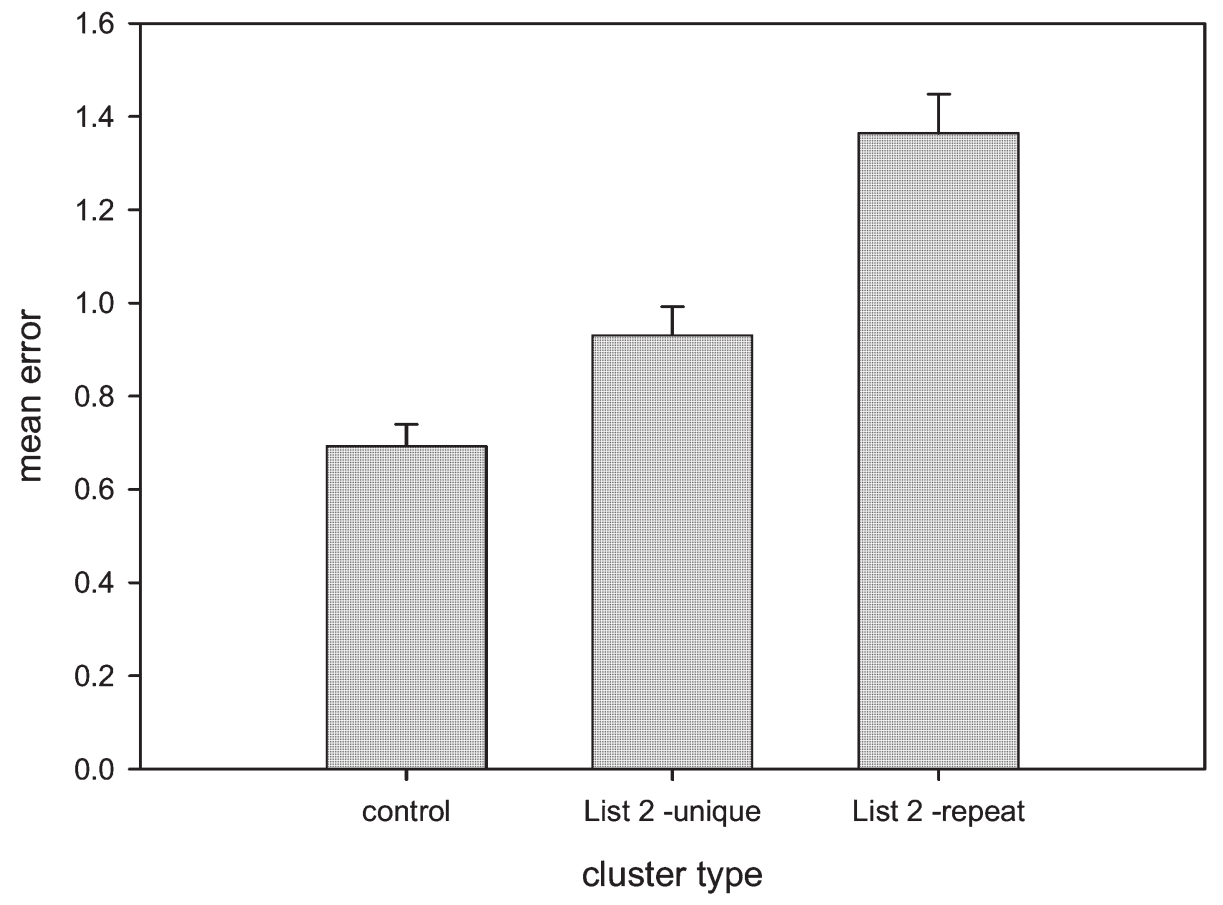

Figure 3. Mean error per cluster for the control condition and the two types of clusters in the experimental condition (unique and repeat) during Experiment 1. Error bars represent standard error 


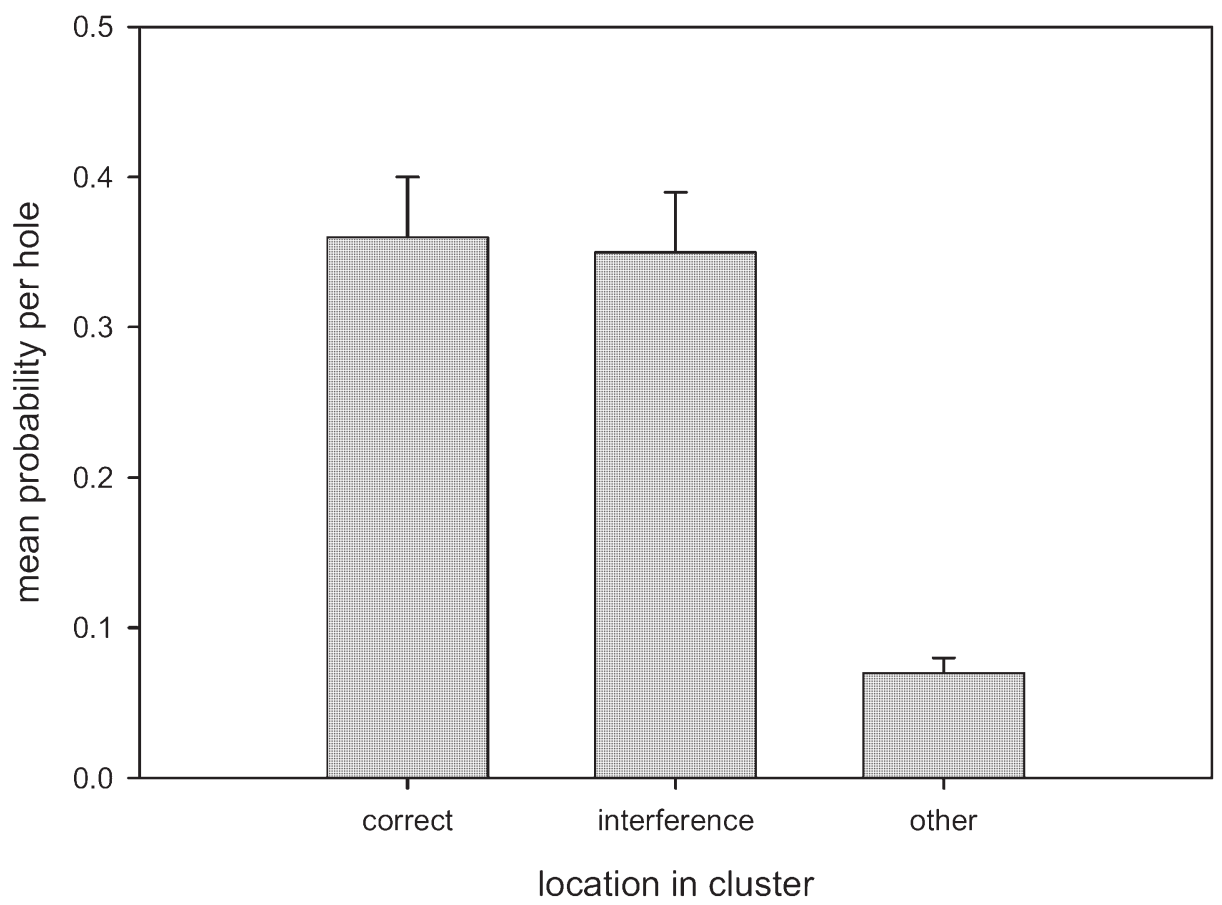

Figure 4. Mean probability of visiting a correct location, interference, or other incorrect location during the first choice within repeat clusters during Experiment 1. Error bars represent standard error

\section{Effects of Reusing Locations During Recall of List 2}

Our results suggest that using a previously rewarded location as an incorrect alternative in a choice test produces the most substantial interference effect for nutcrackers. This is because the highest error rate during List 2 testing was found in repeat clusters that contained a previously rewarded location from List 1. Furthermore, during their first choice in repeat clusters, nutcrackers had a tendency to make mistakes by visiting the previously rewarded location.

By reusing locations between List 1 and 2, we manipulated the amount of similarity between the lists. In the repeat condition, clusters from both List 1 and 2 shared locations in space and shared surrounding cues such as landmarks. Both of these factors may have contributed to the interference effects seen in this experiment because of increased similarity. Increasing the similarity between old and new information often increases the level of interference, which is especially true when information is repeated (Wright et al., 1986). Sands and Wright (1980a, 1980b) found that monkeys made more errors during the recall of lists when the items were chosen from small sample pools in which items were repeatedly reused. Monkeys performed better with lists drawn from large sample pools that included trial-unique stimuli during every trial. During the recall of lists with small sample pools, monkeys made frequent errors by responding to an incorrect stimulus that had been correct during previous lists (Sands \& Wright, 1980a, 1980b). This suggests that animals are most susceptible to interference when the testing samples over multiple trials are most similar to each other.

\section{Effects of Proximity During Recall of List 2}

The high numbers of errors during List 2 testing were due partly to proactive interference from the memory of List 1 loca- tions. The unique condition in our experiment was essentially a replication of the Bednekoff et al. (1997) study. In both studies, the interference condition required the bird to accurately recall locations from two lists that were both near to each other and shared the same environmental cues. Unlike the Bednekoff et al. study, we found that nutcrackers performed more poorly on the second list when given two lists per day.

One key difference between the present study and that of Bednekoff et al. (1997) was that we used shorter temporal intervals between the two lists. We gave the birds 5 min between lists, whereas Bednekoff et al. (1997) gave the birds 2 days between the recovery of the first set and the next set of caches. Other studies suggest that a short interval between lists may enhance interference effects (Cohen, Reid, \& Chew, 1994; Cohen, Sturdy, \& Hicks, 1996). Furthermore, our birds were not allowed to cache seeds or to choose the locations that they needed to remember. In our experiment, we could control for site preferences, which may have affected recall. Our research suggests that the choice of placement, or the recovery order of caches, may be important for nutcrackers to minimize the effects of interference from previous cache sites.

\section{Experiment 2: Retroactive Interference}

In nature, events that occur between caching and recovery could cause retroactive interference. This may include caching and/or recovering food in an area in which food was previously stored before the final recovery of that food. Retroactive interference could also occur if the bird has exposure to previously depleted cache sites when recovering caches.

The purpose of this experiment was to determine whether nutcrackers are susceptible to retroactive interference effects. We predicted that nutcrackers would make more errors when remembering a list if the birds were exposed to an interfer- 


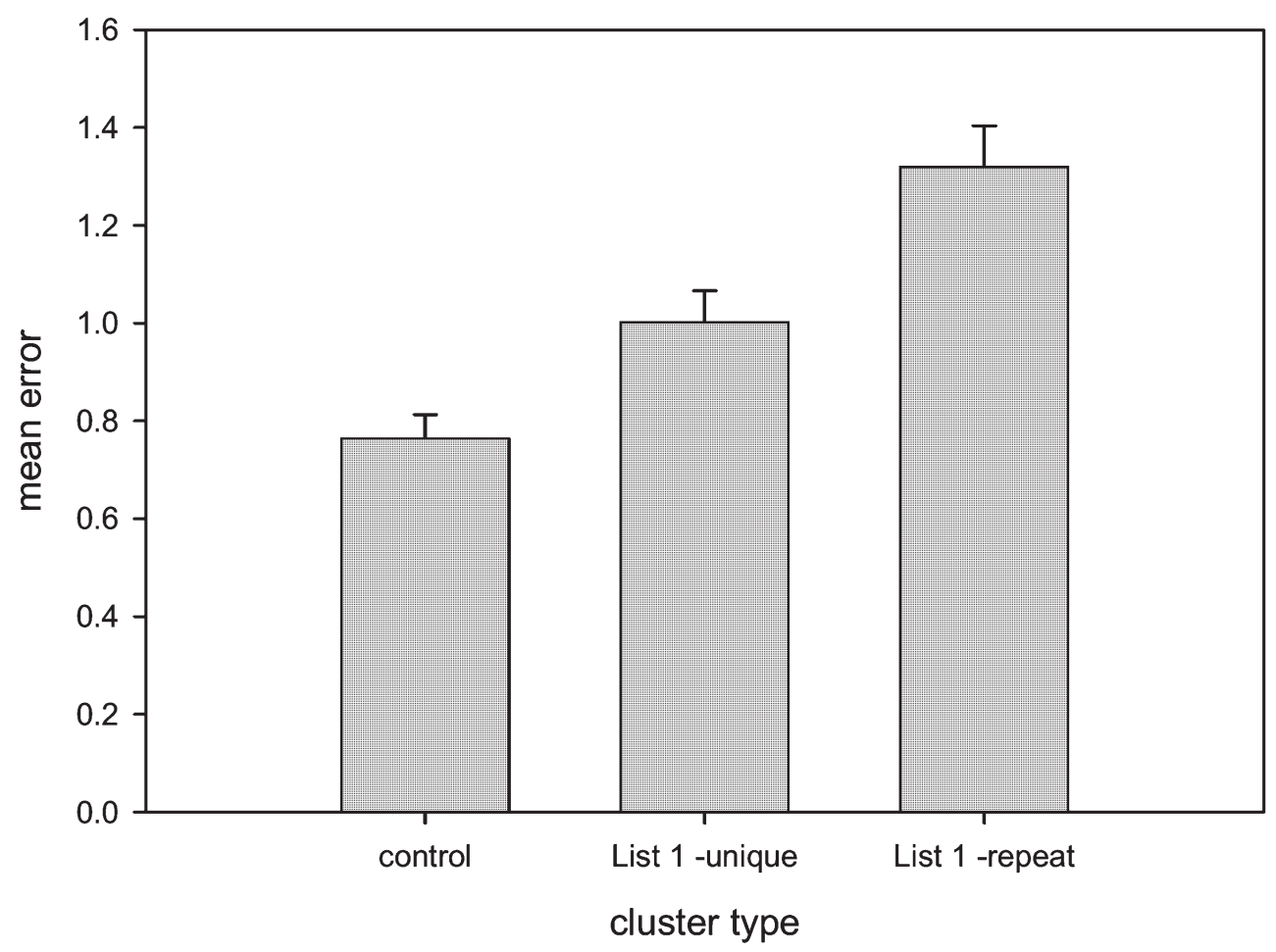

Figure 5. Mean error per cluster for the control condition and the two types of clusters in the experimental condition (unique and repeat) during Experiment 2. Error bars represent standard error

ing list (List 2) between study and recognition of the target list (List 1). Furthermore, we hypothesized that birds would make more errors in List 1 clusters if they contained a previously rewarded location from List 2.

\section{Method}

\section{Subjects and Apparatus}

In Experiment 2, we used the same 6 birds from the training phase in Experiment 1 (the bird with the bad foot recovered and served in this experiment) and the same testing room as in the previous experiment. There was a 6-month interval between the two experiments. During this time, the birds received no further training.

\section{Procedure}

All nutcrackers were given one trial a day and tested in both the control condition (one list a day) and the experimental condition (two lists per day) on alternate days, using a design directly analogous to that of Experiment 1. When given two lists in one day, the birds received the interfering list between the study and recognition phase of the first list (see Table 1). Birds waited in the holding cage for $5 \mathrm{~min}$ between each phase. Two clusters in List 1 were chosen to contain interfering information. Repeat clusters were those that contained incorrect alternatives that were previously rewarded locations in List 2. However, List 2 clusters did not contain a location that had been previously rewarded during List 1 . During a trial, the control list for one squad was the same set of locations as List 1 in the experimental condition. During the control condition, each bird spent $25 \mathrm{~min}$ in the holding cage before recovering seeds from that list (the time it would have taken to conduct the additional list in the experimental condition). During the time spent in the holding cage, the birds were given the same amount of food they would have received if they had been tested with List 2 . All of the birds were tested 5 days a week for 50 days.

\section{Results}

As in the previous experiment, the birds continued to perform more accurately than would be expected by chance, $t(5)=-46.09, p=.001$. There were, however, significant differences in the mean number of errors among the three list types: control, List 1 , and List $2, F(2,5)=15.37, p=.001$. A subsequent Fisher's LSD test revealed that the birds made more errors during List 1 testing $(M=1.13 \pm 0.06)$ than during either List 2 testing $(M=0.75 \pm 0.05)$ or control testing. There were no differences in number of errors between List 2 and control.

When examining the source of errors made when recalling List 1, we compared errors made in unique, repeat, and control clusters. Again, we used the same control clusters from the previous analysis to provide a control comparison for the two cluster types in List 2. Figure 5 shows the mean number of errors during testing of the control, unique, and repeat clusters. There was an effect of cluster type, $F(2,5)=12.04, p=.002$. Using Fisher's LSD, we found that nutcrackers made more errors during repeat cluster testing than during unique cluster testing. Nutcrackers also made more errors during repeat cluster testing than during control cluster testing. However, the number of errors during unique cluster testing did not differ from control.

Figure 6 shows the mean number of first visits to correct, interference, and other locations within a cluster. We also found a significant effect of first choices made in repeat clusters, $F(2,5)=15.29, p=.001$. Fisher's LSD revealed that birds were more likely to visit the correct and interfering location than any other incorrect location in the cluster. 


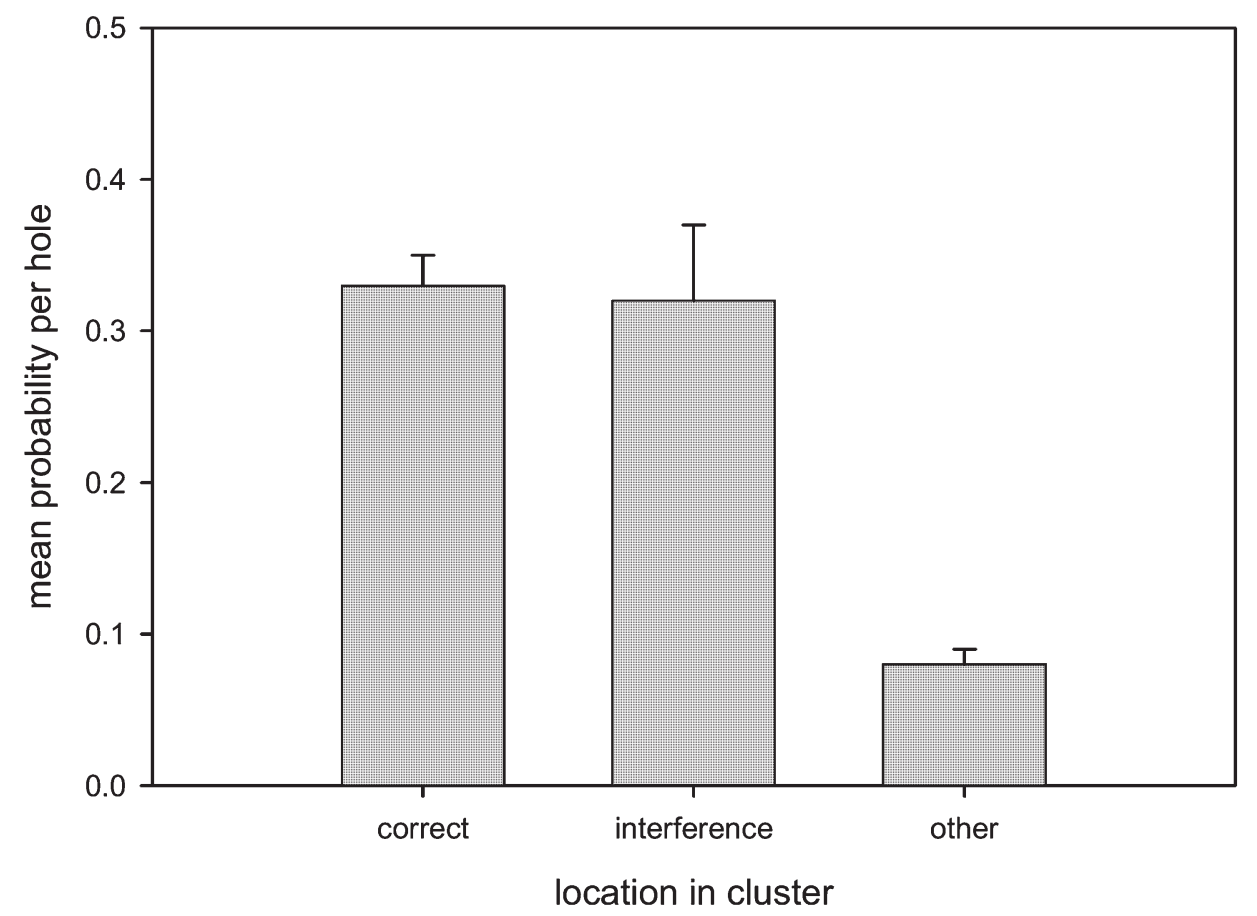

Figure 6. Mean probability of visiting a correct location, interference, or other incorrect location during the first choice within repeat clusters during Experiment 2. Error bars represent standard error

\section{Discussion}

The much lower levels of accuracy observed in the List 1 condition compared with the control condition demonstrate retroactive interference in nutcrackers. This constitutes the first evidence for such an effect during the recall of spatial locations in nutcrackers. Most of the interference was due to nutcrackers making more errors in List 1 clusters, which contained a location that had been rewarded during List 2 .

Testing with unique clusters, however, did not significantly affect performance during the recall of List 1 . These results suggest that nutcrackers are more susceptible to retroactive interference when locations are reused during repeated testing than when the clusters were unique to the trial. It is possible that we did not find decreased performance during recall in unique clusters because retroactive interference is a different process than proactive interference that is not susceptible to this type of interference. Nutcrackers may also be resistant to retroactive interference from nearby but not repeated sites. It is also possible that, because Experiments 1 and 2 were run in succession, interference from unique clusters disappears after repeated testing. However, the birds may have made many errors during unique clusters in Experiment 1 because they were experiencing proactive interference from the intensive training. The 6-month break before Experiment 2 could have helped to minimize this type of interference.

We would like to emphasize caution when attempting to interpret the comparison between the List 2 and the control list in this study. The two lists were not equivalent because the retention interval of List 2 in the experimental condition was 5 min and the retention interval for the control condition was $25 \mathrm{~min}$. Although it is also possible that the study sequence of List 1 proactively interfered with the recall of List 2, List 2 did not include incorrect alternatives from List 1.

\section{General Discussion}

These experiments provide the first clear evidence for the importance of proactive and retroactive interference in the spatial memory of Clark's nutcrackers. We found that interference caused a significant decrement in nutcracker's memory for spatial locations. Furthermore, there were two different sources of interference. We found effects of interference when locations were either close to the target list or were reused in the choice test. First, nutcrackers were extremely susceptible to repeated-item interference effects when tested with two lists in 1 day regardless of whether the interference was proactive or retroactive. Performance was lower in the target list because nutcrackers made more errors in repeat clusters. This was because nutcrackers made many of their first visits to the interfering location, the location that was correct during recall of another list. Second, we demonstrated that nutcrackers were susceptible to proactive interference from clusters that contained unique information in each target cluster. This interference came from prior exposure to the interfering list, which contained locations that were nearby the target locations.

Clark's nutcrackers are highly dependent on stored food and demonstrate excellent performance in food-storing and spatial memory tasks in the laboratory. Previous studies have failed to find evidence of interference in spatial memory during cache recovery (Bednekoff et al., 1997). However, we have found clear evidence of proactive and retroactive interference during an open-room, noncache recovery spatial memory task. There are several methodological reasons that are probably responsible for this difference in results. Our experiments used interlist intervals of minutes, whereas caching studies used intervals of days (e.g., Bednekoff et al., 1997; Kamil \& Balda, 1985). There is evidence to suggest that shorter intervals can increase the effects of interference (Edhouse \& White, 1988). 
Our procedures also allow for more control over factors that may affect the memory of locations. For example, choosing the sample locations, instead of allowing the birds to cache seeds, controls for site preferences (Kamil \& Balda, 1985, 1990). Furthermore, controlling the order of recall will control for output interference effects (Tulving \& Arbuckle, 1966) and whether the birds recover seeds in the order of best-remembered sites first (Kamil \& Balda, 1990). Therefore, our methods minimize variation and control for possible behavioral effects that may affect memory. These methods we have used to study memory in nutcrackers may enhance interference effects that do not occur in a natural cache recovery system. However, these methods could reveal aspects of nutcracker memory that could not otherwise be observed with more naturalistic caching methods.

Another likely reason that we found such strong interference effects is that we maximized the possibility for the effects of interference by increasing the similarity between the interfering and target information (Roberts, 1981; Wright et al., 1986). For example, reusing locations within a trial or between trials has also been shown to produce interference effects (Sands \& Wright, 1980a, 1980b). Additionally, although all rewarded sites were chosen without replacement, we were unable to prevent a sample that was correct from the day before from occurring as one of the alternatives in a choice test. Therefore, we did not measure whether interference effects could also affect accuracy between days. It would be interesting to further examine whether nutcrackers are susceptible to a buildup of proactive interference over days of testing.

Detrimental effects of interference on spatial memory performance are typically seen in experiments in which rats are repeatedly tested in the same maze. For example, Roberts and Dale (1981) found a decrease in radial maze performance as they increased the number of trials the rats were given in the same maze. However, rats appear to be resistant to retroactive interference in tests of memory in radial arm maze experiments (Beatty \& Shavalia, 1980; Cook \& Brown, 1985; Maki, Brokofsky, \& Berg, 1979; Roberts, 1981), which may have to do with the way interference is tested in these experiments. In radial maze experiments, rats are forced to choose a number of arms in the maze, followed by a retention interval in which they are given potentially interfering information and then are tested for their memory of the unvisited arms. Maki et al. (1979) found that exposing rats to "incidental environmental events" (such as changes in illumination, white noise, removal from the maze, feeding, or changes in the odor of the maze) before recall had no effect on maze accuracy. Therefore, it is possible that retroactive interference effects may only occur when spatial information is given before the recognition test.

However, many experiments have also failed to find any evidence of retroactive interference when rats are run in an interpolated maze that is in a different area of the room or in different rooms (Beatty \& Shavalia, 1980; Maki et al., 1979; Roberts, 1981). Roberts (1981) was, however, able to produce retroactive interference effects when the rat was allowed to eat pellets in the arms of the same maze after the prestudy phase. Rats were also more likely to make errors when they ate pellets in arms that were different from the arms given in the forced-choice stage. Roberts argued that exposing the rat to arms in the same maze twice was more likely to cause interference than testing rats in a different maze because the memories from arms in the same maze were encoded with the same cues.
On the basis of our results and the results of Roberts (1981), we conclude that interfering stimuli that are most similar to the target stimuli will produce the largest decrements in performance. We found the largest interference effects when the birds were given the incorrect alternatives from the previous list in the choice test. Simply providing locations from the interfering list near the target list was not enough to produce interference effects.

Finally, the effects of interference from repeatedly used locations could help explain other behavioral phenomenon seen in food-storing birds, such as revisits to emptied cache sites (Balda et al., 1996; Kamil \& Balda, 1985, 1990). Nutcrackers may revisit depleted sites in laboratory experiments because the same environment and caching locations are used repeatedly over several sessions. This could increase the chances of proactive interference occurring between emptied cache sites and the memory of sites that still contain seeds. Laboratory caching experiments have suggested that forcing nutcrackers to cache repeatedly in the same room has an impact on their caching and recovery behavior (Kamil \& Balda, 1990). However, choosing trial-unique sites for each caching session has no adverse effect on nutcracker cache recovery performance (Kamil et al., 1994). Kamil et al. (1993) found that when nutcrackers are recovering seeds, they are most likely to visit a seeded location, then visit depleted sites, and only then visit sites that never contained seeds. This suggests that nutcrackers are able to distinguish between seeded and unseeded sites but may retain different values for each type of site. Nutcrackers may revisit depleted cache sites because they have not yet lost the memory for the emptied site. Kamil et al. (1993) also suggested that the bird could also remember that a particular site was depleted (i.e., "tag" the site as empty). A site that once contained seeds would then retain a higher value than if the site never contained seeds and would thus be visited first (Kamil et al., 1993). Our experiments suggest that nutcrackers' cache recovery performance may also be affected by interference from the memory of depleted sites. Having a repeated location within the choice test significantly increased the number of errors nutcrackers made in repeat clusters. However, in this experiment, we found no evidence that nutcrackers could distinguish between full and depleted locations.

Of particular concern is how researchers can identify whether the nutcracker knows "the rules of the game." That is, how does the experimenter communicate which list the bird is to recall on a given trial? Our birds were trained to treat seeded locations just as they would cache sites. Therefore, once a location was visited during the recognition phase (i.e., depleted), the bird was never rewarded for revisiting that location on a given test day. Nutcrackers can easily learn not to revisit locations just as rats learn to avoid revisits to depleted arms in a radial maze.

The results of these experiments demonstrate the advantages of using highly controlled procedures for studying memory in nutcrackers and other food-storing birds. Using artificial food-finding tasks such as the one we used allows researchers to control behavioral variables that influence memory (e.g., Shettleworth et al., 1990). Our experiments have demonstrated that although Clark's nutcrackers have an excellent memory for spatial locations, they are not immune to the effects of interference. The failure to find evidence for interference with less controlled procedures suggests that there is something important about the way birds cache and/or recover stored food 
that significantly enhances their performance. Further research with serial presentation techniques in open-room settings will help to identify what characteristics of nutcracker memory makes them so well adapted to remembering cache locations.

\section{References}

Balda, R. P. (1980). Recovery of cached seeds by captive Nucifraga caryocatctes.. Zeitschrift fur Tierpsychologie, 52, 331-346.

Balda, R. P., \& Kamil, A. C. (1992). Long-term spatial memory in Clark's nutcracker, Nucifraga columbiana.. Animal Behaviour, 44, 761-769.

Balda, R. P., Kamil, A. C., \& Bednekoff, P. A. (1996). Predicting cognitive capacity from natural history. In V. Nolan Jr. \& E. D. Ketterson (Eds.), Current ornithology (Vol. 13, pp. 33-66). New York: Plenum Press.

Basil, J. A., Kamil, A. C., Balda, R. P., \& Fite, K. V. (1996). Differences in hippocampal volume among food-storing corvids. Brain Behavioral Evolution, 47, 156-164.

Beatty, W. W., \& Shavalia, D. A. (1980). Spatial memory in rats: Time course of working memory and effects of anesthetics. Behavioral and Neural Biology, 28, 454-462.

Bednekoff, P. A., Kamil, A. C., \& Balda, R. P. (1997). Clark's nutcracker (Aves: Corvidae) Spatial memory: Interference effects on cache recovery performance? Ethology, 103, 554-565.

Clayton, N. S. (1995). Development of memory and the hippocampus: Comparison of food-storing and nonstoring birds. Journal of Neuroscience, 15, 2796-2807.

Clayton, N. S., \& Krebs, J. R. (1994). One-trial associative memory: Comparison of food-storing and nonstoring species of birds. Animal Learning \& Behavior, 22, 366-372.

Cohen, J. S., Reid, S., \& Chew, K. (1994). Effects of varying trial distribution, intra- and extramaze cues, and amount of reward on proactive interference in the radial maze. Animal Learning E Behavior, 22, 134-142.

Cohen, J. S., Sturdy, C., \& Hicks, M. (1996). Intratrial proactive interference in rat's serial alternation performance in the radial maze. Animal Learning \& Behavior, 24, 300-309.

Cook, R. G., \& Brown, M. F. (1985). Retroactive interference in rat radial maze performance: The role of point of delay interpolation and the similarity and amount of interpolated material. Animal Learning \& Behavior, 13, 116-120.

Edhouse, W. V., \& White, K. G. (1988). Sources of proactive interference in animal memory. Journal of Experimental Psychology: Animal Behavior Processes, 14, 56-70.

Gibson, B. M., \& Kamil, A. C. (2001). Search for a hidden goal by Clark's nutcrackers (Nucifraga columbiana) is more accurate inside than outside a landmark array. Animal Learning $\mathcal{E}$ Behavior, 29, 234-249.

Goodyear, A. J., \& Kamil, A. C. (2004). Clark's nutcrackers (Nucifraga columbiana) and the effects of goal-landmark distance on overshadowing. Journal of Comparative Psychology, 118, 258-264.

Hampton, R. R., \& Shettleworth, S. J. (1996). Hippocampus and memory in a food-storing and in a nonstoring bird species. Behavioral Neuroscience, 110, 946-964.
Hampton, R. R., Shettleworth, S. J., \& Westwood, R. P. (1998). Proactive interference, recency, and associative strength: Comparisons of black-capped chickadees and dark-eyed juncos. Animal Learning \& Behavior, 26, 475-485.

Healy, S. D., \& Krebs, J. R. (1992). Comparing spatial memory in two species of tit: Recalling a single positive location. Animal Learning \& Behavior, 20, 121-126.

Healy, S. D., \& Krebs, J. R. (1996). Food-storing and the hippocampus in Paridae. Brain, Behavior E Evolution, 47, 195-199.

Kamil, A. C., \& Balda, R. P. (1985). Cache recovery and spatial memory in Clark's nutcrackers (Nucifraga columbiana). Journal of Experimental Psychology: Animal Behavior Processes, 11, 95-111.

Kamil, A. C., \& Balda, R. P. (1990). Differential memory for different cache sites by Clark's nutcrackers (Nucifraga columbiana). Journal of Experimental Psychology: Animal Behavior Processes, 16, 162-168.

Kamil, A. C., Balda, R. P., \& Olson, D. J. (1994). Performance of four seed-caching corvid species in the radial-arm maze analog. Journal of Comparative Psychology, 108, 385-393.

Kamil, A. C., Balda, R. P., Olson, D. J., \& Good, S. (1993). Returns to emptied cache sites by Clark's nutcrackers, Nucifraga Columbiana: A puzzle revisited. Animal Behaviour, 45, 241-252.

Krebs, J., Clayton, N., Healy, S., Cristol, D., Patel, S., \& Jolliffe, A. (1996). The ecology of the avian brain: Food-storing memory and the hippocampus. Ibis, 138, 34-46.

Maki, W. S., Brokofsky, S., \& Berg, B. (1979). Spatial memory in rats: Resistance to retroactive interference. Animal Learning $\mathcal{E}$ Behavior, 7, 25-30.

Olson, D. J., Kamil, A. C., Balda, R. P., \& Nims, P. J. (1995). Performance of four seed-caching corvid species in operant tests of nonspatial and spatial memory. Journal of Comparative Psychology, 109, 173-181.

Roberts, W. A. (1981). Retroactive inhibition in rat spatial memory. Animal Learning \& Behavior, 9, 566-574.

Roberts, W. A., \& Dale, R. H. I. (1981). Remembrance of places lasts: Proactive inhibition and patterns of choice in rat spatial memory. Learning and Motivation, 12, 261-281.

Sands, S. F., \& Wright, A. A. (1980a, August). Primate memory: Retention of serial list items by a rhesus monkey. Science, 209, 938-940.

Sands, S. F., \& Wright, A. A. (1980b). Serial probe recognition performance by a rhesus monkey and a human with 10 and 20 item lists. Journal of Experimental Psychology: Animal Behavior Processes, 6, 386-396.

Shapiro, M. L., \& Olton, D. S. (1994). Hippocampal function and interference. In D. L. Scacter \& E. Tulving (Eds.), Memory systems (pp. 87-117). Cambridge, MA: MIT Press.

Sherry, D., Vaccarino, A. L., Buckenham, K., \& Herz, R. S. (1989). The hippocampal complex of food-storing birds. Brain, Behavior and Evolution, 34, 308-317.

Shettleworth, S. J. (1995). Comparative studies of memory in foodstoring birds: From the field to the Skinner box. In E. Alleva, A. Fasolo, H. P. Lipp, L. Nadel, \& L. Ricceri (Eds.), Behavioral brain research in naturalistic and semi-naturalistic settings (pp. 159-192). Dordrecht, the Netherlands: Kluwer Academic Press. 
Shettleworth, S. J., \& Hampton, R. R. (1998). Adaptive specializations of spatial cognition in food-storing birds? Approaches to testing a comparative hypothesis. In I. Pepperburg, R. Balda, \& A. C. Kamil (Eds.), Animal cognition in nature (pp. 65-98). San Diego, CA: Academic Press.

Shettleworth, S. J., \& Krebs, J. R. (1982). How marsh tits find their hoards: The roles of site preference and spatial memory. Journal of Experimental Psychology: Animal Behavior Processes, 8, 354-375.

Shettleworth, S. J., Krebs, J. R., Healy, S. D., \& Thomas, C. M. (1990). Spatial memory of food-storing tits (Parus ater and $P$. atricapillus): Comparison of storing and nonstoring tasks. Journal of Comparative Psychology, 104, 71-81.

Tomback, D. F. (1980). How nutcrackers find their seed stores. Condor, 82, 10-19.

Tulving, E., \& Arbuckle, T. Y. (1966). Input and output interference in short-term memory. Journal of Experimental Psychology, $72,145-150$.
Vander Wall, S. B. (1982). An experimental analysis of cache recovery in Clark's nutcracker. Animal Behaviour, 30, 84-94.

Vander Wall, S. B. (1990). Food hoarding in animals. Chicago: University of Chicago Press.

Vander Wall, S. B., \& Hutchins, H. E. (1983). Dependence of Clark's nutcracker, Nucifraga columbiana, on conifer seeds during the postfledging period. Canadian Field-Naturalist, 97, 208-214.

Wright, A. A., Santiago, H. C., Sands, S. F., Kendrick, D. F., \& Cook, R. G. (1985, July). Memory processing of serial lists by pigeons, monkeys, and people. Science, 229, 287-289.

Wright, A. A., Urcuioli, P. J., \& Sands, S. F. (1986). Proactive interference in animal memory. In D. F. Kendrick, M. E. Rilling, \& M. R. Denny (Eds.), Theories of animal memory (pp. 101-125). Hillsdale, NJ: Erlbaum. 